\title{
The Relationship between Learning Styles and Career Decision-Making Self-Efficacy among Medicine and Dentistry Students of Ardabil University of Medical Sciences
}

\author{
Robab Farhang, ${ }^{1}$ Ulduz Zamani Ahari, ${ }^{2}$ Samira Ghasemi, ${ }^{2}$ and Aziz Kamran $\mathbb{D}^{3}$ \\ ${ }^{1}$ Department of Endodontics, School of Dentistry, Ardabil University of Medical Sciences, Ardabil, Iran \\ ${ }^{2}$ Department of Oral Medicine, School of Dentistry, Ardabil University of Medical Sciences, Ardabil, Iran \\ ${ }^{3}$ School of Medicine and Allied Medical Sciences, Ardabil University of Medical Sciences, Ardabil, Iran \\ Correspondence should be addressed to Aziz Kamran; aziz_kamran@ymail.com
}

Received 14 October 2020; Revised 24 October 2020; Accepted 30 October 2020; Published 16 November 2020

Academic Editor: Gwo-Jen Hwang

Copyright $(92020$ Robab Farhang et al. This is an open access article distributed under the Creative Commons Attribution License, which permits unrestricted use, distribution, and reproduction in any medium, provided the original work is properly cited.

Background and Objectives. The career decision-making self-efficacy (CDSE) in medical, pharmacy, and dental students is more important than other disciplines due to professional sensitivity, direct involvement in decision-making for the treatment process, and the significant clinical involvement. It is also expected that learning styles can have a significant impact on the academic success, and the CDSE also affects the quality of clinical care. Therefore, the aim of this study was to examine the relationship between the learning styles and the career decision-making self-efficacy among medicine and dentistry students. Materials and Methods. This cross-sectional study was conducted on 235 medical interns and fifth- and sixth-year dental students of Ardabil University of Medical Sciences, Iran. The data were collected using Kolb Learning Style Inventory and Betz and Luzzo career decision-making self-efficacy questionnaire. Statistical tests such as Kolmogorov-Smirnov, Spearman correlation coefficient, Chi-square, one-way ANOVA were used to analyze the data. Results. The mean age of participants was $25.9 \pm 1.30$; a majority of them were dental students (134 persons, 59.3\%), and 92 were medical students (40.7\%). The predominant learning styles in dental and medical students were assimilating (40.3\%) and converging (47.8\%), respectively. There was no significant relationship between students' learning styles and career decision-making self-efficacy and none of its subscales $(P>0.05)$. The Chi-square test results showed that a significant difference was observed between the field of study and learning styles of the participants $(P=0.024)$. Conclusion. This study showed that there was no significant relationship between learning style and career decision-making self-efficacy of the participants.

\section{Introduction}

Learning styles reflect a person's preferred learning style, related to individual differences in mental and personality dimensions [1]. Previous research has highlighted the importance of learning styles [2-4]. It has already been proven that instructional outcomes can vary by considering learning styles [4-6]. Achieving the educational goals requires proper policy making, proper implementation of programs by professors, and proper receipt of this training by students [7]. Medical sciences such as medicine and dentistry are among the fields that need a high attention to the quality of education due to direct interventions performed on human tissue and the impacts on maintaining and preserving human health [8]. The learning process and its quality depend on several factors. Among these, learning patterns that enhance students' learning are important $[8,9]$. A learning style is a unique way to understand and retain information. The ultimate goal of learning is to acquire the desired knowledge and skills [10]. Various models and classification approaches for learning styles have been described in the literature, including the models of David Kleb and Anthony Gregork and Gardner's multiple intelligences theory [11-13]. Nonetheless, most studies have focused on Kolb's learning study inventory (LSI), peculiarly in the the field of medical education [14]. 
The Kolb's LSI model classifies the knowledge acquisition process into four categories: assimilating، accommodating, converging, and diverging. This division is based on four stages of learning, including active experimentation (AE), abstract conceptualization (AC), concrete experience $(\mathrm{CE})$, and reflection observe (RO) [15]. Accommodators favoring concrete experience and the dynamic experimentation are more pragmatic and rapidly adjust to an assortment of circumstances, appreciating new difficulties while depending on their own encounters and others' data. "Assimilators" utilize the two strategies of reflective observation and abstract conceptualization to learn, and these people are more likely to listen to lectures, read content, and explore analytical models. "Convergent" learning is based on abstract conceptualization and active experimentation with the precedence of hypothetical reasoning and deductive problem analysis. They are best at finding reasonable applications for thoughts and hypotheses and pay little attention to the exchange of information between people interested in technical tasks. "Divergers" depend on the concrete experience and reflective observation. They have a lot of creativity and imagination and are interested in communicating with people and are superior to others in seeing situations from different angles [11]. The difference in learning styles of medical students based on their cultural condition has been confirmed despite the difference in their learning styles at home and abroad [16].

One of the basic aspects of human development is career development, which is considered as a particularly crucial element of psychosocial advancement [17]. The term "career" refers to a combination of work tasks that people experience throughout their lives [18]. There are many factors contributing to the individuals' career decision [19]. Self-efficacy beliefs include the psychological processes that can have a significant impact on the acquisition or change of behaviors [20]. Self-efficacy refers to an individual's beliefs about his/her abilities in order to be able to use these abilities to demonstrate behavior that can lead to the production of desirable and acceptable returns. According to Bieschke, people who think they are capable of getting things done are always interested in trying and getting things done successfully [21]. According to theory of social cognitive career, the self-efficacy is defined as one's belief in one's capability to succeed in the career field, which is considered as a fundamental variable that effectively predicts career performance [22]. According to Bandura (2006), career decisionmaking self-efficacy (CDSE) has been very influential in the area of career development as proposed by Taylor and Betz (1983) [23]. Taylor and Betz's (1983) theory is in fact a combination of Crites's career maturity model $(1961,1965)$ and Bandura's theory of self-efficacy (1977) [24].

The fields of medicine and dentistry are related to the health of the community, and enhancing students' knowledge in these fields is associated with improving community health. It is thus important to pay more attention the education and learning of these students. Identifying the learning styles of these students can help determine the ways to improve their education. Also, due to the sensitivity of medical sciences, the CDSE of graduates in these fields is of

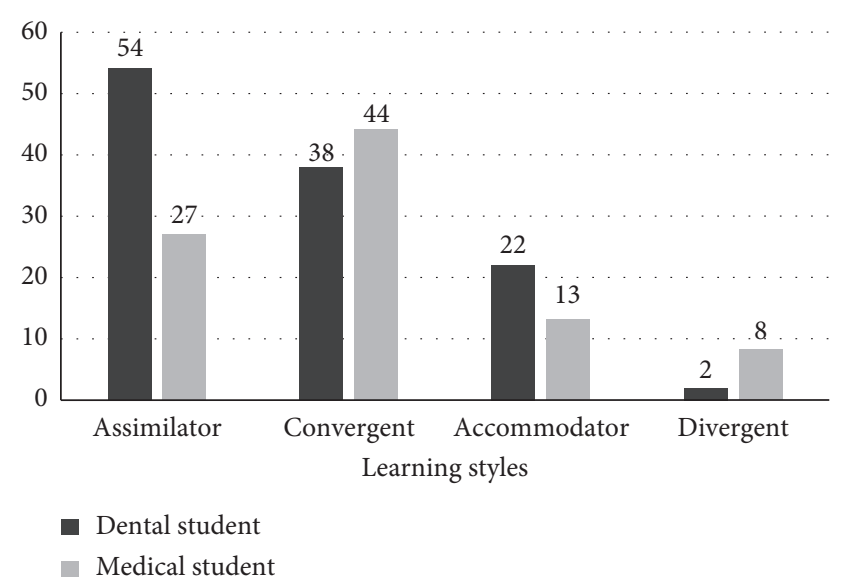

FIGURE 1: The frequency of learning styles of the study participants by the field of study.

special importance. Accordingly, the aim of this study was to examine the relationship between career decision self-efficacy and learning styles of medical and dental students.

\section{Materials and Methods}

This cross-sectional study was conducted on the medical interns and fifth- and sixth-year dental students of Ardabil University of Medical Sciences, Iran, who were selected by census sampling method. After providing the sufficient explanations about objectives of the study, participants were asked to complete the questionnaires accurately and honestly. The data were collected by Kolb Learning Style Inventory, Betz and Luzzo career decision-making self-efficacy scale (CDSE), and demographic questionnaire. Kolb et al. confirmed the validity and reliability of the initial version of the learning styles questionnaire (LQS) [25]. In Iran, various studies examined the validity and reliability of the Persian version of this questionnaire [26-28]. This questionnaire consisted of twelve phrases with four options. Participants rated each phrase on a Likert scale of 1-4 based on their opinions. Individual orientation scores for each learning style were determined according to the relevant benchmarks and charts. The validity and reliability of the CDSE scale have also been confirmed by various studies $[29,30]$. This scale has 25 sentences containing 5 subscales with 5 sentences. Participants rated their success or disapproval of each of the statements on a five-point Likert scale (from not at all to absolutely sure). Statistical tests such as Kolmogorov-Smirnov, Spearman correlation coefficient, Chi-square, and Oone-way ANOVA were used to analyze the data.

\section{Results}

A total of 235 students were participated in this study. 226 out of 235 participants had completed all the questionnaires. The mean age of the subjects was $25.9+1.30$ years. The study population comprised slightly more females than males (51.3\%). Dental and medical students made up 59.3\% and $40.7 \%$ of the participants, respectively. A majority of the students (62.8\%) were living in Ardabil. The GPA average of 
TABLE 1: Association between learning styles and demographic and academic variables of the study participants.

\begin{tabular}{|c|c|c|c|c|c|c|c|}
\hline & Assimilating & Converging & Accommodating & Diverging & Total & $F / X^{2}$ & $P$ value \\
\hline Self appraisal & $13.38 \pm 5.12$ & $13.41 \pm 3.63$ & $13.02 \pm 3.83$ & $11.39 \pm 3.68$ & $13.09 \pm 4.28$ & $1.76^{*}$ & 0.155 \\
\hline Occupational information & $12.69 \pm 3.39$ & $12.57 \pm 3.70$ & $11.57 \pm 3.68$ & $10.96 \pm 3.62$ & $12.26 \pm 3.61$ & $2.24^{*}$ & 0.083 \\
\hline Goal selection & $12.80 \pm 3.06$ & $12.93 \pm 3.24$ & $12.40 \pm 3.40$ & $11.07 \pm 3.80$ & $12.57 \pm 3.31$ & $2.46^{*}$ & 0.064 \\
\hline Planning & $12.54 \pm 3.42$ & $12.21 \pm 4.07$ & $11.28 \pm 3.79$ & $11.50 \pm 3.42$ & $12.10 \pm 3.73$ & $1.20^{*}$ & 0.308 \\
\hline Problem solving & $12.54 \pm 3.41$ & $12.18 \pm 3.74$ & $10.80 \pm 4.36$ & $10.89 \pm 4.09$ & $11.93 \pm 3.81$ & $2.58^{*}$ & 0.054 \\
\hline CDMSE & $63.96 \pm 15.55$ & $63.32 \pm 16.60$ & $59.08 \pm 17.62$ & $55.82 \pm 17.11$ & $61.96 \pm 16.60$ & $2.24^{*}$ & 0.084 \\
\hline Age & $26.17 \pm 1.33$ & $25.89 \pm 1.38$ & $25.88 \pm 1.15$ & $25.53 \pm 1.03$ & $25.94 \pm 1.30$ & $1.83^{*}$ & 0.142 \\
\hline GPA & $16.23 \pm 1.08$ & $16.07 \pm 1.00$ & $16.28 \pm 1.10$ & $16.43 \pm 1.13$ & $16.20 \pm 1.06$ & $0.94^{*}$ & 0.420 \\
\hline \multicolumn{8}{|l|}{ Gender } \\
\hline Man & $42(38.2 \%)$ & $40(36.4 \%)$ & $18(16.4 \%)$ & $10(9.1 \%)$ & $110(100 \%)$ & $2.31^{* *}$ & 0.509 \\
\hline Woman & $39(33.6 \%)$ & $42(36.2 \%)$ & $17(14.7 \%)$ & $18(15.5 \%)$ & $116(100 \%)$ & & \\
\hline \multicolumn{8}{|l|}{ Study field } \\
\hline Dental & $54(40.3 \%)$ & $38(28.4 \%)$ & $22(16.4 \%)$ & $20(14.9 \%)$ & $134(100 \%)$ & $9.41^{* *}$ & 0.024 \\
\hline Medical & $27(29.3 \%)$ & $44(47.8 \%)$ & $13(14.1 \%)$ & $8(8.7 \%)$ & $92(100 \%)$ & & \\
\hline \multicolumn{8}{|l|}{ Native status } \\
\hline Native & $53(37.3 \%)$ & $50(35.2 \%)$ & $21(14.8 \%)$ & $18(12.7 \%)$ & $142(100 \%)$ & $0.501^{* *}$ & 0.919 \\
\hline Nonnative & $28(33.3 \%)$ & $32(38.1 \%)$ & $14(16.7 \%)$ & $10(11.9 \%)$ & $84(100 \%)$ & & \\
\hline Total & $81(35.8 \%)$ & $82(36.3 \%)$ & $35(15.5 \%)$ & $28(12.4 \%)$ & $226(100 \%)$ & & \\
\hline
\end{tabular}

*One-way ANOVA. ** Chi-square.

TABLE 2: The relationship between CDMSE and academic/demographic variables.

\begin{tabular}{lcccc}
\hline & Mean & Standard deviation & $\mathrm{T} / r^{2}$ & $P$ value \\
\hline Gender & & & & \\
Man & 62.96 & 16.44 & $0.876^{*}$ & 0.382 \\
Woman & 61.02 & 16.77 & & \\
\hline Study field & & & & \\
Dental & 62 & 16.53 & $0.34^{*}$ & 0.973 \\
Medical & 61.92 & 16.80 & & \\
\hline Native status & 61.52 & 17.13 & $0.518^{*}$ & 0.605 \\
Native & 62 & 15.74 & & \\
Non-native & 62.71 & - & $0.064^{* *}$ & 0.339 \\
Age & - & - & $0.060^{* *}$ & 0.371 \\
GPA & - & & & \\
\hline
\end{tabular}

*Independent $T$-test. ${ }^{* *}$ Pearson correlation coefficient.

students was 16.20. The frequency of different learning styles of the participants based on the field of study is shown in Figure 1.

The results of Chi-square test showed that there was a significant difference between the field of study and learning styles of the participants $\left(P=0.024, X^{2}=9.41, \mathrm{~d} f=3\right)$. The predominant learning styles in dental and medical students were assimilating (40.3\%) and converging (47.8\%), respectively. The mean scores of CDSE and all its subscales in both medicine and dentistry students were average scores $(61.96 \pm 16.60)$. No significant differences were found between the participants with respect to gender, age, grade point average, and native status with learning styles $(P>0.05)(1)$. There is no significant relationship between students' learning styles and career decision-making selfefficacy and none of its subscales based on one-way ANOVA test $(P>0.05)$ (Table 1$)$. Also, there was no significant difference between the study participants with respect to gender, age, grade point average, native status, and field of study $(P>0.05)$ (Table 2$)$. Self appraisal and problem solving had the highest and lowest mean of CDSE dimension with self-efficacy scores, respectively, 13.9 and 11.93.

\section{Discussion}

In the present study, the dominant learning style was "assimilating" in dental students and "converging" in medical students, and there was a significant correlation between learning styles and field of study of the participants. A review of past studies has shown that the results are controversial. A study performed by ALQahtani and Al-Gahtani in Saudi Arabia reported that "diverging" is the most common learning style among dental students [31]. While the studies of Meyari et al. [16] and Kalbasi et al. [32] showed that most medical students have a convergent learning style that was consistent with our findings. In their study, Nasirzadeh et al. found no difference between medical and dental students with respect to the learning styles, and most students had a converging learning style [33]. On the other hand, studies performed by Engels and de Gara [34] in Canada and Gurpinar et al. [35] in Turkey reported that the learning style of most medical students was assimilating. Our results are consistent with the studies conducted in Turkey; thus, the differences in students' learning styles may be due to cultural differences.

In the present study, there was no statistically significant association between sex, age, grade point average, native status, and learning styles. The results of the study of ALQahtani and Al-Gahtani [31] confirmed that no significant association was found between age, sex, and students' learning style. In contrast, Adesunloye et al.'s study demonstrated that LSI Kolb is gender-sensitive [10]. The findings show small but real difference in learning styles between the females and males: abstract conceptualization was preferred by men more than women. However, the two studies that 
used early versions of the LSI found no difference between learning styles by gender [36,37]. The study of Hosseini et al. [38] and Al-Qarafi et al. [31] found no significant relationship between learning styles and GPA of dental students which was consistent with our results.

The learning strategy of "assimilators" includes abstract conceptualization and reflective observation [39]. Furthermore, an assimilator is keen on ideas and theories while not paying much attention to their application [25]. However, assimilators are highly skilled in systematic planning and logic and are interested in lecturing, reading, and conceptualizing theoretical models. The preferred method of learning in convergent students is both abstract conceptualization and active experimentation. Due to their high problem-solving skills, they are able to actually implement theories. They are interested in lab sessions and experiments $[11,25,39]$.

In the field of career decision-making self-efficacy, in all aspects of self-appraisal, occupational information, goal selection, planning, and problem solving, students showed a moderate level, meaning that medical and dental students have a relatively good assessment of their abilities. They strive for their professional goals and do not give up quickly; they set short-term, medium-term, and long-term goals for themselves and find their ideal jobs or job opportunities and are able to overcome obstacles to achieving goals logically. But this self-efficacy is not at a high level and will be vulnerable. These findings are consistent with those of Shafiee et al.'s study [29]. We found no significant association between gender and CDMS. The findings of some studies were similar $[29,40]$, but some studies showed a significant relationship between gender and CDMS [41, 42]. Therefore, the findings were controversial.

The findings of this study showed no relationship between learning styles and CDMS of students. Considering that this topic is new and no study has been done in this field so far, it is not possible to be satisfied with the results of this study, and it is recommended that further studies are needed in order to examine relationship between learning styles and CDMS. Attention to two key variables in medical education, considering the importance of career decision-making of students in this field and the special place of this profession in the health and well-being of society, is one of the strengths of this study. Therefore, it is important to find ways to improve CDMS in medical and dental students. Studies conducted by Wang et al. [43] and Breaux [44] showed that group training and cooperative education have a significant effect on improving students' CDMS. One of the limitations of this study is relying on the questionnaire as the only tool for data collection and not using semistructured interviews to discover the live experiences of students in this field. In order to reduce the effect of the mentioned limitation, the most relevant and comprehensive tools in the field of learning styles and career decision-making self-efficacy were selected.

\section{Recommendation}

Kolb mentioned that assimilators prefer structured, systematic, logical, and comprehensive information, but convergers preferred learning by PBL method, case analysis, and brainstorming [35]. Given that evidence has shown that students' learning styles change in relation to time, we suggest that, at the beginning of each course, students' learning styles can be identified to tailor their teaching methods to their curricula. There is a hypothesis for us that more learning happens in groups with the same learning styles. We suggest that more studies be done on this topic. And if the hypothesis is proved, student groupings in clinical education should be considered based on the learning style factor.

\section{Conclusion}

This study examined the relationship between learning style and career decision-making self-efficacy and found no relationship between the two variables. As this was the first study conducted in this field, the results are not conclusively reliable, and further studies are needed.

\section{Data Availability}

We can make data available on request through a data access committee, institutional review board.

\section{Conflicts of Interest}

The authors declare that they have no conflicts of interest.

\section{Acknowledgments}

This study was approved by the Research Ethics Committee of Ardabil University of Medical Sciences with approval ID: IR.ARUMS.REC.1399.141.

\section{References}

[1] F. Romanelli, E. Bird, and M. Ryan, "Learning styles: a review of theory, application, and best practices," American Journal of Pharmaceutical Education, vol. 73, no. 1, p. 9, 2009.

[2] D. M. Chapman and J. G. Calhoun, "Validation of learning style measures: implications for medical education practice," Medical Education, vol. 40, no. 6, pp. 576-583, 2006.

[3] C. A. Coker and S. J. Pedersen, "Context and test-retest reliability of Kolb's learning style inventory," Psychological Reports, vol. 95, no. 1, pp. 180-182, 2004.

[4] J. D. Baker, J. E. Cooke, J. M. Conroy, H. R. Bromley, M. F. Hollon, and C. C. Alpert, "Beyond career choice: the role of learning style analysis in residency training," Medical Education, vol. 22, no. 6, pp. 527-532, 1988.

[5] R. D. Richard, B. F. Deegan, and J. C. Klena, "The learning styles of orthopedic residents, faculty, and applicants at an academic program," Journal of Surgical Education, vol. 71, no. 1, pp. 110-118, 2014.

[6] L. M. Dibartola, M. K. Miller, and C. L. Turley, "Do learning style and learning environment affect learning outcome?" Journal of Allied Health, vol. 30, no. 2, pp. 112-115, 2001.

[7] D. Chalmers and R. Fuller, "Teaching for learning at university: theory and practice," Teaching and Learning in Higher Education Series, Stylus Publishing, Sterling, VA, USA, 1996.

[8] F. Coffield, D. Moseley, E. Hall et al., Learning Styles and Pedagogy in Post-16 Learning: A Systematic and Critical 
Review, Learning and Skills Development Agenc, Argyll Street, London, UK, 2004.

[9] H. Pashler, M. McDaniel, D. Rohrer, and R. Bjork, "Learning styles," Psychological Science in the Public Interest, vol. 9, no. 3, pp. 105-119, 2008.

[10] B. A. Adesunloye, O. Aladesanmi, M. Henriques-Forsythe, and C. Ivonye, "The preferred learning style among residents and faculty members of an internal medicine residency program," Journal of the National Medical Association, vol. 100, no. 2, pp. 172-177, 2008.

[11] A. Y. Kolb and D. A. Kolb, The Kolb Learning Style InventoryVersion 3.12005 Technical Specifications, Hay Resource Direct, vol. 200, no. 72, , pp. 166-171, Boston, MA, USA, 2005.

[12] H. Gardner, Frames of Mind: The Theory of Multiple Intelligences, Hachette Uk, London, UK, 2011.

[13] L. Raab and A. J. Adam, "The university college model: a learning-centered approach to retention and remediation," New Directions for Institutional Research, vol. 125, pp. 86-106, 2005.

[14] J. Fredette, C. O’Brien, C. Poole, and J. Nomura, "Do emergency medicine residents and faculty have similar learning styles when assessed with the Kolb learning style assessment tool?" Delaware Medical Journal, vol. 87, no. 4, p. 109, 2015.

[15] D. Kolb, The Kolb Learning Style Inventory 4.0: Guide to Theory, Psychometrics, Research, and Application, Experience Based Learning Systems, Hawaii, USA, 2016.

[16] A. Meyari, A. Sabouri Kashani, M. Gharib, and M. Beiglarkhani, "Comparison between the learning style of medical freshmen and fifthyear students and its relationship with their educational achievement," Strides in Development of Medical Education, vol. 6, no. 2, pp. 110-118, 2010.

[17] A. Eryilmaz and T. Mutlu, "Yasam boyu gelisim yaklasimi perspektifinden kariyer gelisimi ve ruh sagligi/career development and mental health from the perspective of life-span development approach," Psikiyatride Guncel Yaklasimlar, vol. 9, no. 2, p. 227, 2017.

[18] D. E. Super, "A life-span, life-space approach to career development," Journal of Vocational Behavior, vol. 16, no. 3, pp. 282-298, 1980.

[19] Y. I. Li, R. J. Hazler, and J. Trusty, "Relational self-construal as a moderator of social support in career decision making," The Career Development Quarterly, vol. 65, no. 1, pp. 44-56, 2017.

[20] A. Bandura, "The explanatory and predictive scope of selfefficacy theory," Journal of Social and Clinical Psychology, vol. 4, no. 3, pp. 359-373, 1986.

[21] K. J. Bieschke, "Research self-efficacy beliefs and research outcome expectations: implications for developing scientifically minded psychologists," Journal of Career Assessment, vol. 14, no. 1, pp. 77-91, 2006.

[22] N. E. Betz, "Career self-efficacy: exemplary recent research and emerging directions," Journal of Career Assessment, vol. 15, no. 4, pp. 403-422, 2007.

[23] A. Bandura, "Adolescent development from an agentic perspective," Self-efficacy Beliefs of Adolescents, vol. 5, pp. 1-43, 2006.

[24] K. M. Taylor and N. E. Betz, "Applications of self-efficacy theory to the understanding and treatment of career indecision," Journal of Vocational Behavior, vol. 22, no. 1, pp. 63-81, 1983.

[25] D. A. Kolb, R. E. Boyatzis, and C. Mainemelis, "Experiential learning theory: previous research and new directions," Perspectives on Thinking, Learning, and Cognitive Styles, vol. 1, no. 8, pp. 227-247, 2001.
[26] R. Sarchami and S. Hossaini, Relationship of Learning Styles with Educational Progress of Nursing Students in Qazvin, Qazvin University of Medical Sciences, Qazvin, Iran, 2004.

[27] V. Zamanzadeh, L. Valizadeh, F.A. Eskandar, and A. Nasim, "Nursing and midwifery students' learning styles in tabriz medical university," Iranian Journal of Medical Education, vol. 6, no. 2, pp. 136-140, 2006.

[28] A. Saif and M. Hosseini, “Comparison of students' learning style regarding to their gender, educational grade and university major," Quarterly Journal of Research and Planning in Higher Education, vol. 7, no. 1, pp. 42-48, 2001.

[29] M. Shafiei, G. Salimi, and Z. Mokhtari, "Research self-efficacy and career decision-making self-efficacy of students at shiraz university of medical sciences: an explanatory model," Iranian Journal of Medical Education, vol. 18, pp. 49-59, 2018.

[30] N. E. Betz and D. A. Luzzo, "Career assessment and the career decision-making self-efficacy scale," Journal of Career Assessment, vol. 4, no. 4, pp. 413-428, 1996.

[31] D. A. ALQahtani and S. M. Al-Gahtani, "Assessing learning styles of Saudi dental students using Kolb's Learning Style Inventory," Journal of Dental Education, vol. 78, no. 6, pp. 927-933, 2014.

[32] S. Kalbasi, N. Mohsen, S. Gholamreza, and P. Ali, "Medical student's learning styles in birjand university of medical sciences," Strides in Development of Medical Education, vol. 5, no. 1, p. 10, 2008.

[33] F. Nasirzadeh, A. Heidarzadeh, M. Shirazi, R. Farmanbar, and A. Monfared, "Assessing learning styles of students in guilan university of medical sciences, 2013," Research in Medical Education, vol. 6, no. 1, pp. 29-39, 2014.

[34] P. T. Engels and C. de Gara, "Learning styles of medical students, general surgery residents, and general surgeons: implications for surgical education," BMC Medical Education, vol. 10, no. 1, pp. 1-6, 2010.

[35] E. Gurpinar, H. Bati, and C. Tetik, "Learning styles of medical students change in relation to time," Advances in Physiology Education, vol. 35, no. 3, pp. 307-311, 2011.

[36] G. Piane, R. J. Rydman, and A. J. Rubens, "Learning style preferences of public health students," Journal of Medical Systems, vol. 20, no. 6, pp. 377-384, 1996.

[37] S. J. Cavanagh, K. Hogan, and T. Ramgopal, "The assessment ofstudent nurse learning styles using the Kolb Learning Styles Inventory," Nurse Education Today, vol. 15, no. 3, pp. 177-183, 1995.

[38] S. M. Hosseini, H. Amery, A. Emadzadeh, and S. Babazadeh, "Dental students' educational achievement in relation to their learning styles: a cross-sectional study in Iran," Global Journal of Health Science, vol. 7, no. 5, p. 152, 2015.

[39] D. A. Kolb, Experience as the Source of Learning and Development, Prentice Hall, Upper Sadle River, NJ, USA, 1984.

[40] R. R. Kelly and T. Hatcher, "Decision-making self-efficacy and barriers in career decision making among community college students," Community College Journal of Research and Practice, vol. 37, no. 2, pp. 103-113, 2013.

[41] W. Kang, W.-C. Kim, and J.-H. Kim, "A study on the relationship between job seeking stress and career decision-making self-efficacy in students of department of dental technology," Journal of Korean Acedemy of Dental Technology, vol. 38, no. 3, pp. 247-256, 2016.

[42] J.-W. Lee, N.-Y. Lee, and Y.-S. Eo, "Path analysis of major satisfaction, clinical competence, career decision-making selfefficacy, and career decision level in undergraduate nursing students," Journal of the Korea Academia-Industrial Cooperation Society, vol. 19, no. 1, pp. 311-320, 2018. 
[43] J.-1. Wang, D.-j. Zhang, and J.-j. Shao, "Group training on the improvement of college students'career decision-making self-efficacy," Health, vol. 2, no. 06, p. 551, 2010.

[44] A. H. Breaux, The Impact of Cooperative Education Participation on Career Indecision, Career Decision-Making Self-Efficacy and Career Decision-Making Style Among College Students, Temple University, Philadelphia, PA, USA, 2004. 